Article

\title{
Influence of Endogenous Factors of Food Matrices on Avidin-Biotin Immunoassays for the Detection of Bacitracin and Colistin in Food
}

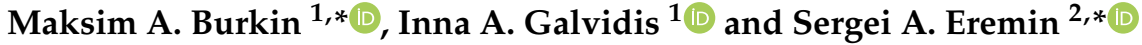 \\ 1 Immunology Department, I. Mechnikov Research Institute for Vaccines and Sera, 105064 Moscow, Russia; \\ galvidis@yandex.ru \\ 2 Faculty of Chemistry, M. V. Lomonosov Moscow State University, Leninsky Gory, 1, 119991 Moscow, Russia \\ * Correspondence: burma68@yandex.ru (M.A.B.); eremin_sergei@hotmail.com (S.A.E.); \\ Tel.: +7-495-9172753 (M.A.B.)
}

check for

updates

Citation: Burkin, M.A.; Galvidis, I.A.; Eremin, S.A. Influence of Endogenous Factors of Food Matrices on Avidin-Biotin Immunoassays for the Detection of Bacitracin and Colistin in Food. Foods 2022, 11, 219 https://doi.org/10.3390/ foods11020219

Academic Editor: Simon Haughey

Received: 18 December 2021

Accepted: 12 January 2022

Published: 13 January 2022

Publisher's Note: MDPI stays neutral with regard to jurisdictional claims in published maps and institutional affiliations.

Copyright: (C) 2022 by the authors. Licensee MDPI, Basel, Switzerland. This article is an open access article distributed under the terms and conditions of the Creative Commons Attribution (CC BY) license (https:// creativecommons.org/licenses/by/ $4.0 /)$.

\begin{abstract}
Strept)avidin-biotin technology is frequently used in immunoassay systems to improve their analytical properties. It is known from clinical practice that many (strept)avidin-biotin-based tests provide false results when analyzing patient samples with a high content of endogenous biotin. No specific investigation has been carried out regarding possible interferences from avidin $(\mathrm{AVI})$ and biotin $\left(\mathrm{B}_{7}\right)$ contained in food matrices in (strept)avidin-biotin-based immunoanalytical systems for food safety. Two kinds of competitive ELISAs for bacitracin (BT) and colistin (COL) determination in food matrices were developed based on conventional hapten-protein coating conjugates and biotinylated BT and COL bound to immobilized streptavidin (SAV). Coating SAV$\mathrm{B}_{7}-\mathrm{BT}$ and SAV-B $-\mathrm{COL}$ complexes-based ELISAs provided 2- and 15-times better sensitivity in BT and COL determination, corresponding to 0.6 and $0.3 \mathrm{ng} / \mathrm{mL}$, respectively. Simultaneously with the determination of the main analytes, these kinds of tests were used as competitive assays for the assessment of AVI or $B_{7}$ content up to 10 and $1 \mathrm{ng} / \mathrm{mL}$, respectively, in food matrices (egg, infant milk formulas enriched with $\mathrm{B}_{7}$, chicken and beef liver). Matrix-free experiments with $\mathrm{AVI} / \mathrm{B}_{7}$-enriched solutions showed distortion of the standard curves, indicating that these ingredients interfere with the adequate quantification of analytes. Summarizing the experience of the present study, it is recommended to avoid immunoassays based on avidin-biotin interactions when analyzing biosamples containing these endogenous factors or enriched with $\mathrm{B}_{7}$.
\end{abstract}

Keywords: bacitracin; colistin; biotinylated hapten coating; immunoassay; matrix biotin and avidin interference; food contaminants

\section{Introduction}

The interaction of (strept)avidin protein and biotin (vitamin $\mathrm{B}_{7}$ ) is widely used in various bioanalytical systems, in particular, in immunoassays [1]. Due to the high affinity $\left(K_{\mathrm{D}} \approx 10^{-15} \mathrm{M}\right)$ and binding valence between this protein (four binding sites) and the vitamin, they are successfully applied as immunoreagent labels to provide an additional functionality [2], for oriented immobilization/presentation [3], as well as to accelerate the interaction [4] or enhance the output signal in immunoassays of various designs [5,6]. In this regard, the involvement of the (strept)avidin-biotin system is one of the main strategies for increasing the sensitivity of immunoassay [7].

In a wide panel of commercial (strept)avidin-biotin-based immunoassay systems used in clinical practice for diagnostic purposes, it has been found that the presence of endogenous biotin in patients' biofluids can interfere with the analysis, leading to false results and, consequently, to misdiagnosis and patient mismanagement [8,9]. However, with a dietary intake of about 35-70 $\mu \mathrm{g} \mathrm{B}_{7} /$ day, the blood $\mathrm{B}_{7}$ level in healthy subjects $(0.12-0.36 \mathrm{nM})$ [10] has a negligible interfering effect on (strept)avidin-biotin assays. At 
the same time, excessive consumption as a result of therapy for a number of disorders (multiple sclerosis, phenylketonuria, biotinidase deficiency) or incorporation in "Hair, Skin, and Nails" cosmetic formulas may lead to $\mu \mathrm{M} \mathrm{B}_{7}$ blood levels, which can significantly distort the results of (strept)avidin-biotin-based tests [9].

The (strept)avidin-biotin technology is equally popular in immunoassays for food safety control [11-13]. However, researchers have not yet been concerned about the possibility that avidin and biotin in the matrix could interfere with the detection of a wide range of analytes in food. Avidin (AVI) is a known protein component in egg white, whereas biotin is widely distributed in different natural foodstuffs. Foods relatively rich in biotin include egg yolk, liver, some vegetables [14], and the majority of biotin in meats and cereals appears to be protein-bound [10]. Thus, these endogenous components of the matrix, the content of which reaches ppb-ppm levels in many analyzed natural foods [15], can represent a serious obstacle in immunoassays based on (strept)avidin-biotin interaction.

In this regard, the objective of the present study was the assessment of the influence of these factors on newly developed ELISA systems based on the coating of biotinylated haptens for the determination of the antibiotics bacitracin and colistin in food matrices rich in $\mathrm{AVI}$ and $\mathrm{B}_{7}$ components.

Bacitracin (BT) [MW = 1422.7] and colistin (COL) [MW = 1155.4] are both cyclic peptide antibiotics (Figure 1) used in veterinary and human medicine. BT is produced by strains of Bacillus licheniformis and functions as an anti-Gram-positive agent, inhibiting bacterial cell wall biosynthesis [16]. Colistin is a product of the biosynthesis of Paenibacillus polymyxa, has a wide Gram-negative spectrum, and kills bacteria mainly through the disruption of bacterial outer membrane integrity, resulting from the binding with LPS [17].

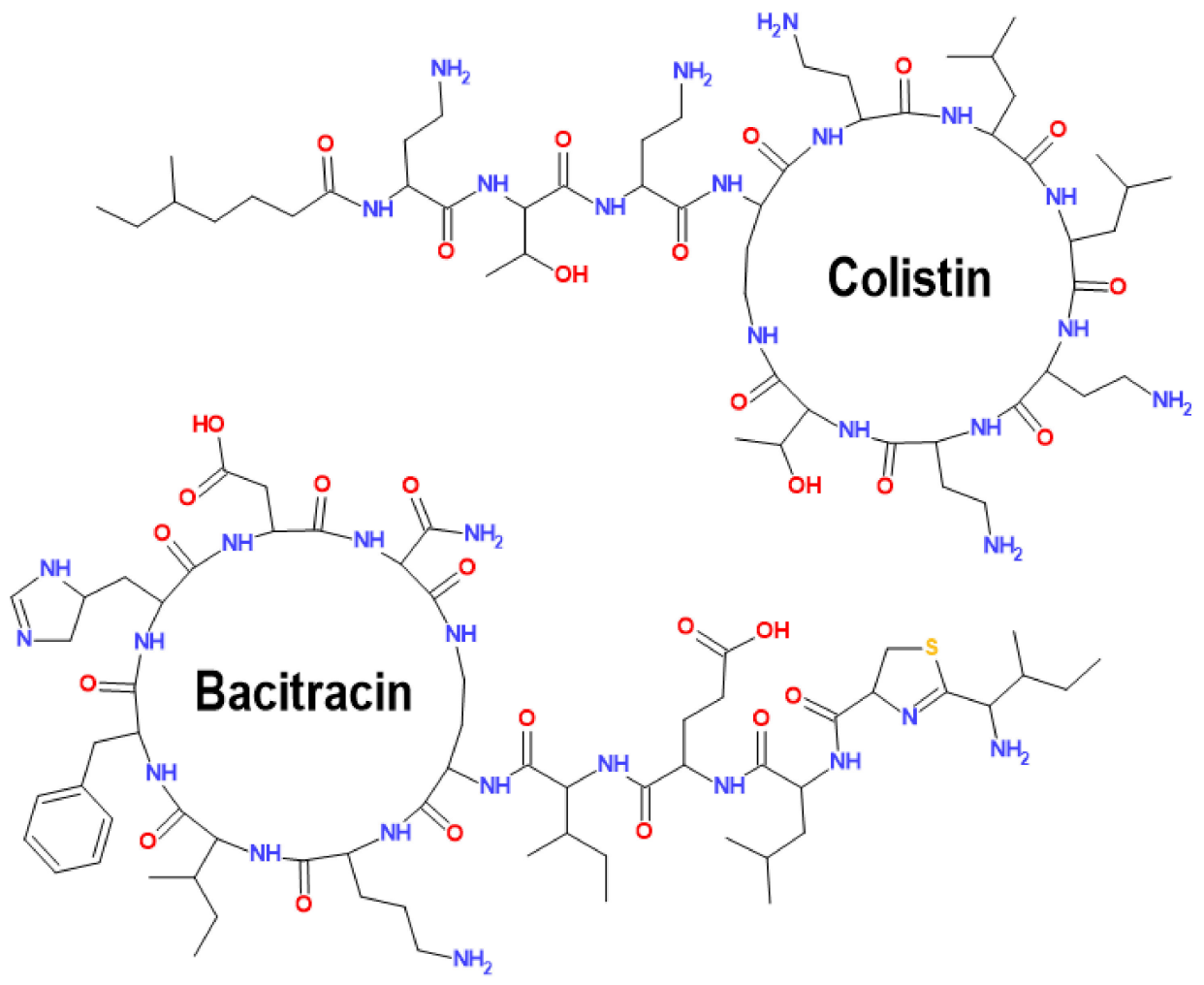

Figure 1. Structural formulas of the peptide antibiotics bacitracin and colistin.

To expand their antibacterial action, these antibiotics can be used together, potentiating each other's activity [18]. Their use in farm animals and a proper withdrawal period should be controlled, so that the residual content of these antibiotics in agricultural products does not exceed the established acceptable threshold (Table 1). 
Table 1. Limitations of residual bacitracin (BT) and colistin (COL) content in foodstuff established by the European Union (EU) and the Eurasian Economic Union (EAEU).

\begin{tabular}{lcccc}
\hline \multirow{2}{*}{ Foodstuffs } & \multicolumn{2}{c}{ MRLs $(\mu \mathrm{g} / \mathbf{k g})$ in EU [19] } & \multicolumn{2}{c}{ MRLs $(\mu \mathrm{g} / \mathbf{k g})$ in EAEU [20] } \\
\cline { 2 - 5 } & BT & COL & BT & COL \\
\hline Milk & 100 & 50 & NE & 50 \\
Eggs & NE & 300 & $<20$ & 300 \\
Meat, Fish, Poultry & $150^{*}$ & 150 & $<20$ & 150 \\
Liver & $150^{*}$ & 150 & $<20$ & 150 \\
Kidney & $150^{*}$ & 200 & $<20$ & 200 \\
\hline
\end{tabular}

${ }^{*}$ rabbit; ${ }^{* *}$ not established.

Among the methods intended for the detection of food contamination with residues of the antibiotics BT and COL, immunochemical methods, in addition to physicochemical techniques [21], are described [22-24]. However, no method involves the (strept)avidinbiotin technology.

\section{Materials and Methods}

\subsection{Chemicals}

Colistin (COL) and polymyxin B (PMB) sulphates were obtained from AppliChem (Darmstadt, Germany). Bacitracin (BT), colistin methanesulphonate (CMS), 1-ethyl-3(3-dimethylaminopropyl)carbodiimide (EDC), N-hydroxysuccinimide (NHS), biotin $\mathrm{N}$ hydroxysuccinimide ester (NHS- $\mathrm{B}_{7}$ ), caprylic acid, bovine serum albumin (BSA), gelatin (GEL) horseradish peroxidase (HRP), and dimethylformamide (DMF) were purchased from Chimmed (Moscow, Russia). Avidins from Streptomyces avidini (streptavidin, SAV) and from egg white (AVI) were from Calbiochem (USA). Goat anti-rabbit IgG antibodies conjugated to HRP (GAR-HRP) were purchased from Imtek Ltd. (Moscow, Russia). Rabbit antisera against BSA-PMB and BSA-BT were prepared and described earlier $[25,26]$, and IgG fractions were isolated using the caprylate-sulphate ammonium method according to a described procedure [27].

\subsection{Preparation of Biotinylated Analytes}

NHS- $B_{7}$ was dissolved in anhydrous DMF $(10 \mathrm{mg} / \mathrm{mL})$, added dropwise to solutions of BT, COL, and PMB in $0.05 \mathrm{M}$ carbonate-bicarbonate buffer (CBB, pH 9.6) at a molar ratio (1:1), and stirred $1 \mathrm{~h}$ at RT using a magnet stirrer. The biotinylated peptides were supplemented with equal volumes of glycerol and stored as $0.1 \mathrm{mM}\left(\mathrm{B}_{7}\right)$ solutions at $-20{ }^{\circ} \mathrm{C}$ until use.

\subsection{Preparation of the Heterologous Coating Antigen GEL-BT(ae)}

BT $(1.42 \mathrm{mg}, 1 \mu \mathrm{mol})$ in $0.284 \mathrm{~mL}$ DMF was added to EDC and NHS (2.5 eq of each) from $10 \mathrm{mg} / \mathrm{mL}$ solutions in DMF and stirred for $1.5 \mathrm{~h}$. After activation of the carboxy groups, BT taken in 10- and 30-fold molar excesses over GEL (4 mg, $25 \mathrm{nmol})$ in CBB (pH 9.6) was added dropwise and stirred for $2 h$ at RT. Unconjugated hapten was removed by dialysis against water.

\subsection{Preparation of the Heterologous Coating Antigen GEL(pi)-PMB}

The glycoprotein GEL was oxidized with sodium periodate and conjugated to amines of PMB as a result of reductive amination, according to procedure described in [25]. GEL ( $4 \mathrm{mg}, 25 \mathrm{nmol})$ and sodium periodate $(1 \mathrm{mg}, 5 \mu \mathrm{mol})$ in $0.5 \mathrm{~mL}$ of distilled water were mixed using a magnetic stirrer for $15 \mathrm{~min}$. The oxidized GEL was dialyzed overnight against water at $4{ }^{\circ} \mathrm{C}$ and then added to the solution of PMB in CBB (pH 9.5) taken in 10and 30-fold molar excess over the protein. After $2 \mathrm{~h}$ of stirring with a magnetic stirrer, $0.1 \mathrm{~mL}$ of sodium borohydride solution $(2 \mathrm{mg} / \mathrm{mL})$ was added to the reaction mixture, which was stirred for another $2 \mathrm{~h}$. The resulting conjugates were dialyzed against water for 2 days at $4{ }^{\circ} \mathrm{C}$. 


\subsection{Competitive ELISAs Based on the Coating Complex SAV-Biotinylated Hapten and Coated Conjugates}

SAV was adsorbed on 96-well high-binding Costar plates (Corning, USA) from 1.0$3.0 \mu \mathrm{g} / \mathrm{mL}$ solutions in $\mathrm{CBB}$ at $4{ }^{\circ} \mathrm{C}$. After overnight coating, the plates were washed three times with 0.15 M PBS (pH 7.2) containing $0.05 \%$ Tween 20 (PBST) and filled with biotinylated antibiotics $\left(B_{7}, 100-0.1 \mathrm{nM}\right)$. The interaction of SAV and $B_{7}$-hapten was carried out for $1 \mathrm{~h}$ at $37^{\circ} \mathrm{C}$. Alternatively, a one-step coating could be carried out using a mixture of SAV and $\mathrm{B}_{7}$-hapten previously prepared in PBS and coated overnight. The plates with the immobilized hapten were then washed and used for a conventional indirect competitive ELISA based on coated hapten-protein conjugates using specific rabbit anti-hapten antibodies and GAR-HRP [28]. Antibodies added to the wells in the working concentration in 1\% BSAPBST $(0.1 \mathrm{~mL})$ were incubated for $1 \mathrm{~h}$ on an ST-3 L plate shaker (ELMI Ltd., Latvia) at $25^{\circ} \mathrm{C}$. Antibody binding at zero analyte concentration $\left(\mathrm{B}_{0}\right)$ was maximal and dose-dependently inhibited in the presence of free analyte $(B, 0.01-1000 \mathrm{ng} / \mathrm{mL})$. Bound antibodies were detected using GAR-HRP $\left(1 \mathrm{~h}, 37^{\circ} \mathrm{C}\right)$ and a TMB-containing substrate mixture $\left(0.5 \mathrm{~h}, 25^{\circ} \mathrm{C}\right)$. The enzymatic reaction was terminated by the addition of $2 \mathrm{M} \mathrm{H}_{2} \mathrm{SO}_{4}$, and the absorbance was read at $450 \mathrm{~nm}$ using a LisaScan spectrophotometer (Erba Mannheim, Czech Republic). The standard curves were plotted as 'relative antibody binding $\mathrm{B} / \mathrm{B}_{0}, \%$ vs. analyte concentration' using GraphPad Prism 8 Software and served for the measurement of antibiotics in food matrices. The analyte concentrations $\left(\mathrm{IC}_{50}\right)$ causing $50 \%$ inhibition of antibody binding served as assay sensitivity values as well as to determine the cross-reactivity (CR) of analogs according to the equation: $\mathrm{CR}=\mathrm{IC}_{50}$ MAIN ANALYTE $/ \mathrm{IC}_{50}$ ANALOGUE $\times 100 \%$.

\subsection{Assessment of $A V I$ and $B_{7}$ in Food Matrices}

$\mathrm{AVI}$ and $\mathrm{B}_{7}$ influence and their content in some food matrices were estimated by the ELISAs based on biotinylated hapten-based coating antigens. Standards of AVI or $B_{7}$ as well as these components in food matrices could inhibit the binding of $B_{7}$-haptens to coated SAV in a dose-dependent manner. Thus, the solutions of standards/samples were added to SAVcoated wells together with $\mathrm{B}_{7}$-hapten and incubated for $1 \mathrm{~h}$ at $25^{\circ} \mathrm{C}$. After this competition stage, the assay was completed as described above. Standard-generated plots served to assess the content of AVI and B7 in food matrices and their effect on (strept)avidin-based assays.

For testing eggs, homogenates were prepared from the contents of eggs by vigorous stirring with a magnetic stirrer. Several samples were tested for $A V I / B_{7}$ content. Before analysis in the developed ELISA, the homogenates were diluted 100 times with PBST.

Aliquots of milk were centrifuged for $5 \mathrm{~min}$ at $10,000 \mathrm{rpm}(7500 \times \mathrm{g})$ to separate and remove milk fat. Then, the samples, diluted 100 times with PBST, were analyzed in ELISAs.

Liver samples from chicken and beef were homogenized using a blender. Portions of the homogenates $(1 \mathrm{~g})$ were vigorously stirred in $4 \mathrm{~mL}$ PBST. The obtained extracts were centrifuged at $3000 \mathrm{rpm}$, and the supernatants were diluted 20-fold with the assay buffer.

\section{Results and Discussion}

\subsection{Assessment of the SAV-Biotinylated Hapten Complexes as Coating Antigens}

The optimization of immunoassay parameters is based on choosing the right ratio between antibody and antigen concentrations. A small-molecule analyte immunoassay, generally a competitive assay, involves the conjugated forms of the antigen. The hapten load in the conjugate can be influenced by the coupling ratio between the hapten and the carrier/enzyme, the presence of available functional groups in the latter, and the conditions of conjugation. Since the final hapten load is difficult to predict, the optimization requires the comparison of conjugates with different loads and the selection of the best one [29]. Thus, a comparison of BT/COL coating conjugates prepared from 10- and 30-fold molar excesses of hapten over GEL showed that a lower hapten loading increased the assay sensitivity, which was confirmed by our earlier observations [30,31]. 
As an alternative hapten immobilization approach, a stable complex between SAV coated on the plates and biotinylated hapten was formed. The degree of hapten immobilization on the plates could be controlled more finely by simply titrating $B_{7}$-hapten on the high-affinity binder SAV (Figure 2). The best sensitivity was obtained when using $3 \mathrm{nM}$ solutions of biotinylated haptens and corresponding antibody dilutions, providing an absorbance level of 0.8-1.2.
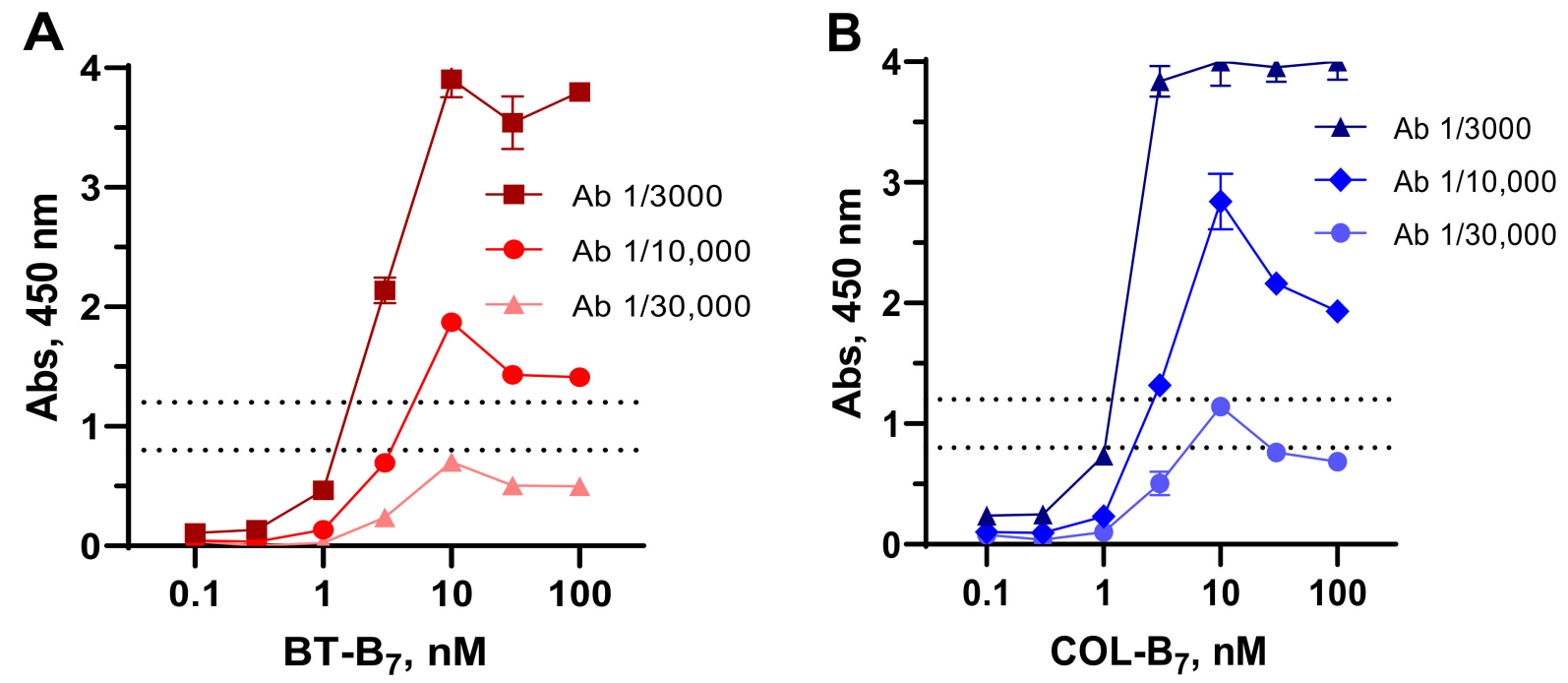

Figure 2. Checkboard titration of $B T-B_{7}(A)$ and $C O L-B_{7}(B)$ on coated streptavidin detected by serially diluted anti-BT (A) and anti-PM (B) antibodies (Ab) in ELISA. The dashed lines indicate an absorbance range of $0.8-1.2$.

Thus, two kinds of hapten immobilization, (1) hapten-protein conjugates and (2) coating SAV-hapten- $\mathrm{B}_{7}$ complexes were considered in the present study and compared in assay systems for the determination of the peptide antibiotics BT and COL. As shown in Figure 3, the coated complex contributed to a slight increase in the sensitivity of BT determination. The $\mathrm{IC}_{50}$ value of $\mathrm{SAV}-\mathrm{B}_{7}-\mathrm{BT}$ ELISA was $0.57 \mathrm{vs}$. that of $1.4 \mathrm{ng} / \mathrm{mL}$ of GEL-BT(ae). A more pronounced effect was observed in relation to COL determination.
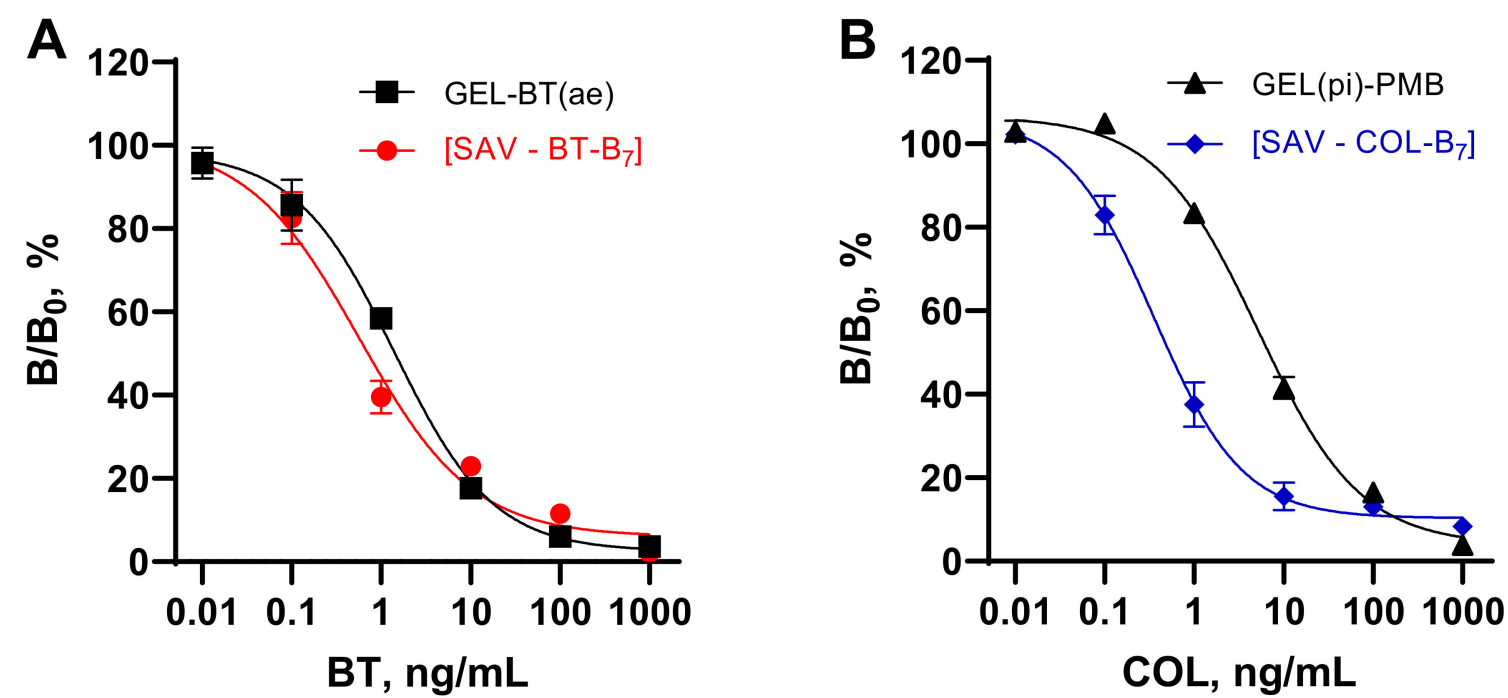

Figure 3. Competitive ELISAs for bacitracin (A) and colistin (B) based on hapten-protein conjugates (empty symbols) and complexes formed between streptavidin (SAV) and biotinylated $\left(\mathrm{B}_{7}\right)$ hapten (filled symbols). 
The $\mathrm{IC}_{50}$ value of $5.2 \mathrm{ng} / \mathrm{mL}$ achieved in the ELISA based on GEL(pi)-PMB could be improved up to $0.34 \mathrm{ng} / \mathrm{mL}$ when using the SAV-B $7-\mathrm{COL}$ complex. Thus, the SAVmediated coating of the biotinylated hapten allowed for a finer optimization of the density of the hapten on the plates compared to the hapten load achieved on the conjugate. The orientation of the hapten into the well volume could also contribute to its steric accessibility and better reactivity in comparison with determinants of the conjugate partly hidden as a result of coating. The improved sensitivity of BT and COL determination achieved using this coating technique was comparable to and more often exceeded that in other reports [22-24].

\subsection{Specificity of the Developed $S A V-B_{7}-B T$ and $S A V-B_{7}-C O L-B a s e d ~ E L I S A s$}

The specificity of the developed tests for BT and COL was assessed by the crossreactivity of related analogs, other cyclic peptide antibiotics, and antibiotics of different families, whose concentration is regulated in food (Table 2). Among the examined substances, cross-reactivity was only found for bacitracin complexed with zinc ions $(67 \%)$ in the anti-BT assay. The other examined substances did not interfere with antibody binding.

Table 2. Specificity of the ELISAs developed based on coated biotinylated haptens.

\begin{tabular}{|c|c|c|c|c|}
\hline \multirow{3}{*}{ Analyte } & \multicolumn{4}{|c|}{ Competitive ELISA Based on Coated Complexes } \\
\hline & \multicolumn{2}{|c|}{ SAV-B $\mathbf{B}_{7}-\mathbf{B T}$} & \multicolumn{2}{|c|}{ SAV-B ${ }_{7}-\mathrm{COL}$} \\
\hline & $\mathrm{IC}_{50}, \mathrm{ng} / \mathrm{mL}$ & $\mathrm{CR}, \%$ & $\mathrm{IC}_{50}, \mathrm{ng} / \mathrm{mL}$ & CR, \% \\
\hline Bacitracin A & 0.57 & 100 & $>10,000$ & $<0.01$ \\
\hline Zn-bacitracin & 0.85 & 67 & $>10,000$ & $<0.01$ \\
\hline Colistin & $>10,000$ & $<0.01$ & 0.34 & 100 \\
\hline Colistin MS & $>10,000$ & $<0.01$ & 9.2 & 3.7 \\
\hline Polymixin B & $>10,000$ & $<0.01$ & 1.5 & 22.4 \\
\hline Actinomycin D & $>10,000$ & $<0.01$ & $>10,000$ & $<0.01$ \\
\hline Vancomicin & $>10,000$ & $<0.01$ & $>10,000$ & $<0.01$ \\
\hline Virginiamycin M1 & $>10,000$ & $<0.01$ & $>10,000$ & $<0.01$ \\
\hline Virginiamycin S1 & $>10,000$ & $<0.01$ & $>10,000$ & $<0.01$ \\
\hline Tetracyclin & $>10,000$ & $<0.01$ & $>10,000$ & $<0.01$ \\
\hline Erythromycin & $>10,000$ & $<0.01$ & $>10,000$ & $<0.01$ \\
\hline Tylosin & $>10,000$ & $<0.01$ & $>10,000$ & $<0.01$ \\
\hline Lasalocid & $>10,000$ & $<0.01$ & $>10,000$ & $<0.01$ \\
\hline Salinomycin & $>10,000$ & $<0.01$ & $>10,000$ & $<0.01$ \\
\hline Lincomycin & $>10,000$ & $<0.01$ & $>10,000$ & $<0.01$ \\
\hline Neomycin & $>10,000$ & $<0.01$ & $>10,000$ & $<0.01$ \\
\hline
\end{tabular}

The values for the main analyte are highlighted in bold; $\mathrm{IC}_{50}$, half-inhibition concentration; $\mathrm{CR}$, cross-reactivity.

SAV-B 7 -COL-coated ELISA, a heterologous hapten-based assay format, also showed higher COL cross-reactivity $(100 \%)$ compared to immunizing hapten, PMB $(22 \%)$, as did the coated COL-conjugate heterologous assay format [25]. Colistin MS is a prodrug form with blocked amine groups, so it was poorly recognized by the antibody. However, as a result of hydrolysis in vivo, CMS was converted into COL and could be detected as active drug [32].

\subsection{Assessment of Extraneous Avidin Influence on the Assay}

AVI and AVI analogs with biotin-binding activity can be found in the eggs of birds, reptiles, and amphibians [33-35]. Bacterial AVI analogs are SAV-isolated from Streptomyces avidinii [36], and rhizavidin from the root nodule nitrogen-fixing bacteria Rhizobium etli [37]. Tamavidins and Lentiavidins are other representatives derived from edible Tamogitake (Pleurotus citrinopileatus) [38] and Shiitake mushrooms (Lentinula edodes) [39]. All of these biotin-binding proteins and numerous recombinant products have moderate to extremely high affinity for biotin $\left(\mathrm{Kd}=10^{-7}-10^{-16} \mathrm{M}\right)$; therefore, they can interfere with the "SAV /AVI- $B_{7}$ " interaction when present in a sample. Because of this, the effect 
of extraneous AVI on ELISAs in the detection of BT and COL using the coated SAV- $\mathrm{B}_{7}-$ hapten complex was examined. This effect was investigated in different stages of the assay. Figure 4 (dashed lines) demonstrates that extraneous AVI $(1-100,000 \mathrm{ng} / \mathrm{mL}$ ) could inhibit the formation of the complexes SAV-BT- $\mathrm{B}_{7}$ and SAV-COL- $\mathrm{B}_{7}$ in a dose-dependent manner (stage 1). Therefore, the developed assay systems could simultaneously serve as competitive assays for AVI detection. No evident effect at stages 2 and 3 was found when $\mathrm{SAV}-\mathrm{B}_{7}$ complexes were already formed. Thus, interference from extraneous AVI may be a drawback for assay formats involving "coated antibody-hapten-B ${ }_{7}$ " or "coated hapten-antibody-B ${ }_{7}$ ", where AVI can interact with unblocked biotin.
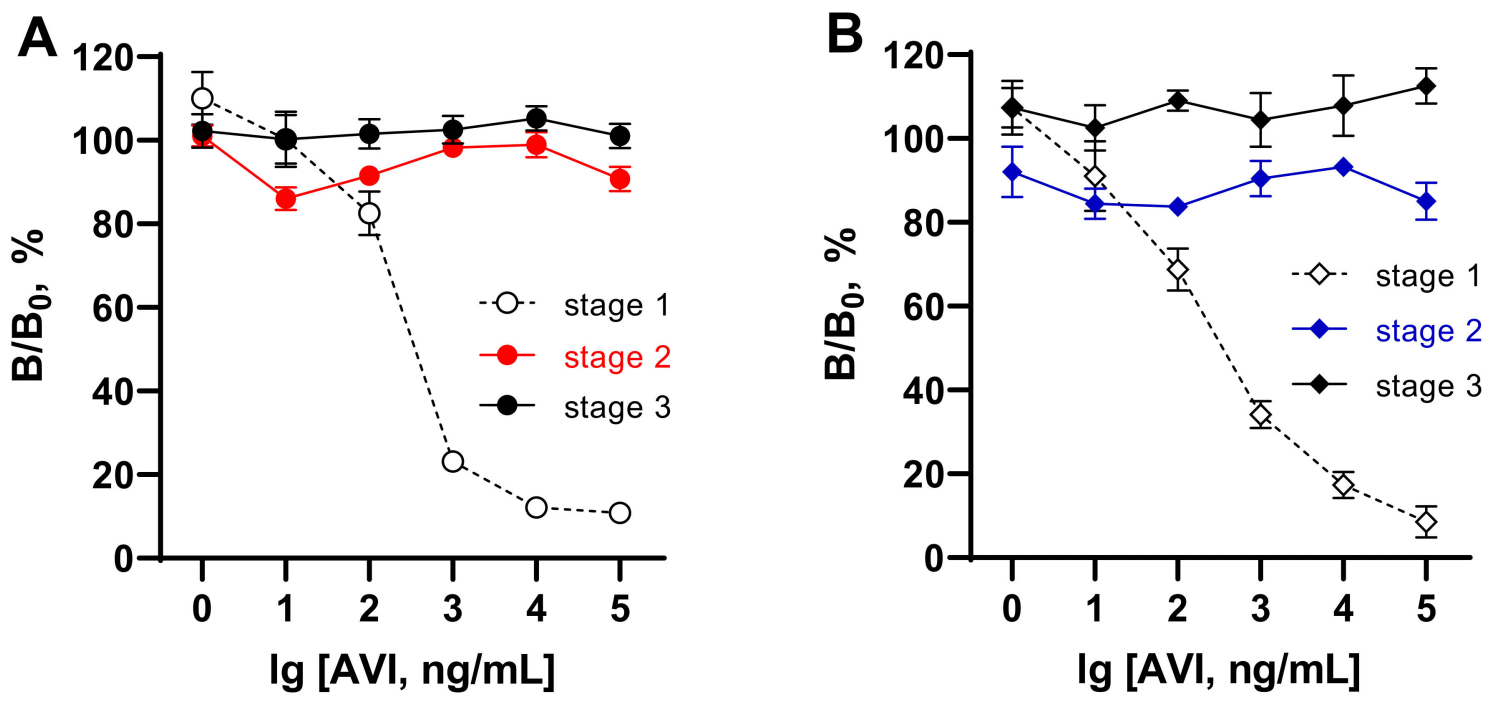

Figure 4. Influence of extraneous AVI on different stages of ELISAs for bacitracin (A) and colistin (B) based on coated complexes formed between SAV and biotinylated hapten. Complex formation between coated SAV and BT/COL-B antibody-GAR-HRP interaction (stage 3).

\subsection{Assessment of Extraneous Biotin Influence on the Assay}

Mammals cannot synthesize biotin but depend on dietary intake from microbial and plant sources [10]. Nevertheless, $B_{7}$ uptake, accumulation in tissues, especially in the liver, and renal reabsorption of $\mathrm{B}_{7}$ determine its presence in animal-derived food. The tissues richest in biotin are chicken and beef liver $(0.4-1.9 \mu \mathrm{g} / \mathrm{g})$, egg yolk $(0.3 \mu \mathrm{g} / \mathrm{g})$, fish $(0.05-0.1 \mu \mathrm{g} / \mathrm{g})$, while the majority of $B_{7}$ in meat is protein-bound [15]. The mentioned $B_{7}$ content is sufficient to cause an undesirable interference in (strept)avidin-biotin-based immunoassay.

The possible interference from extraneous $B_{7}$ was examined in different stages of the developed assays as reported above for the assessment of AVI influence. As seen in Figure 5, the presence of $B_{7}$ in the test samples up to $10,000 \mathrm{ng} / \mathrm{mL}(50 \mu \mathrm{M})$ could disrupt the formation of the complex between $\mathrm{SAV}$ and $\mathrm{B}_{7}$ at concentrations $>1 \mathrm{ng} / \mathrm{mL}$ (Figure 5 , stage 1). When the complexes between $\mathrm{SAV}$ and $\mathrm{B}_{7}$-hapten were already formed in stage 1 , the influence of extraneous $B_{7}$ could not strongly affect the binding in the assay ranging between 80 and $110 \%$ (Figure 5, stage 2,3).

Thus, these experiments showed that samples with moderate to high AVI or $\mathrm{B}_{7}$ content cannot be analyzed using tests in which the analyte is detected during $\mathrm{SAV}-\mathrm{B}_{7}$ complexation due to the strong influence of endogenous matrix factors. In the assay design considered in this work, the recognition of the analyte by antibodies (stage 2) was separated from the $\mathrm{SAV}-\mathrm{B}_{7}$ interaction (stage 1 ) to minimize the possible influence of endogenous $\mathrm{AVI} / \mathrm{B}_{7}$ from the matrix. 

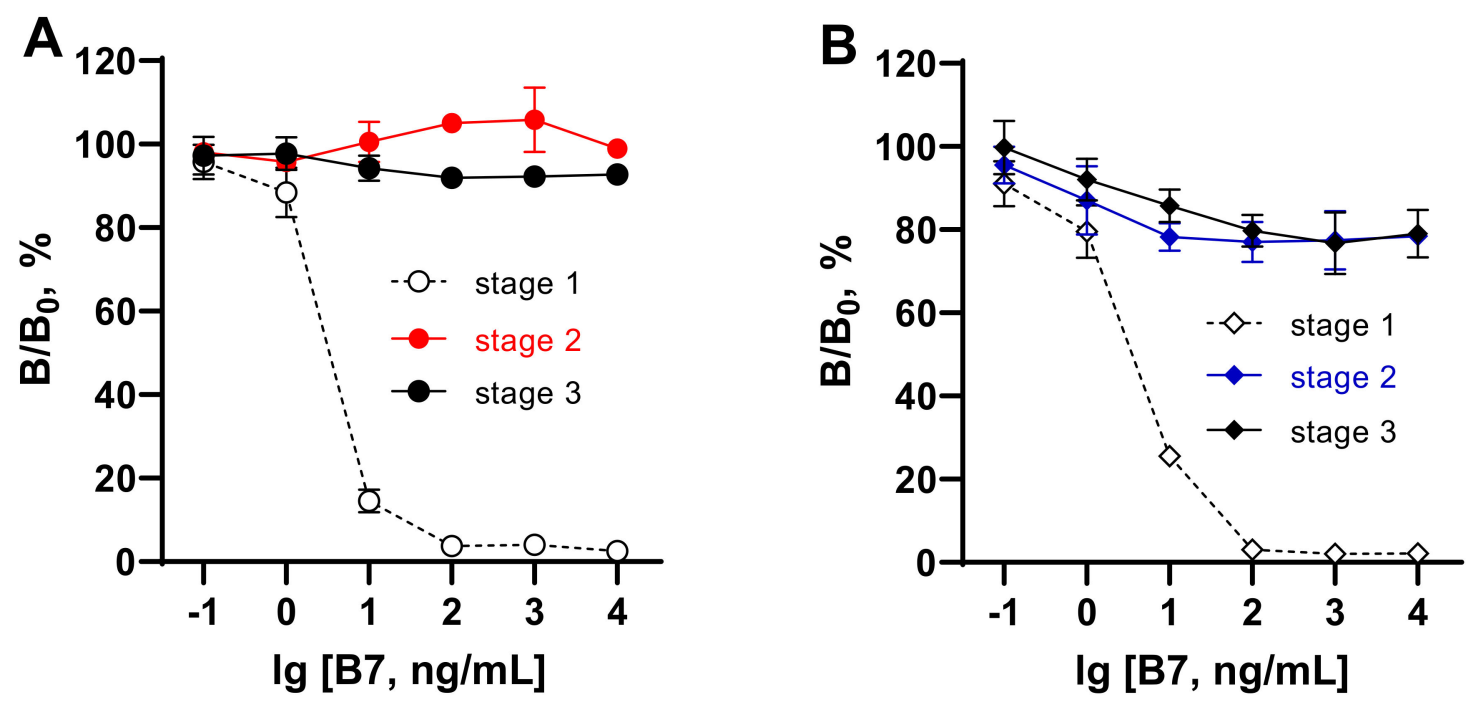

Figure 5. Influence of extraneous biotin $\left(B_{7}\right)$ in different stages of ELISAs for bacitracin (A) and colistin (B) based on coated complexes formed between SAV and biotinylated hapten. Complex formation between coated SAV and BT/COL-B 7 (stage 1), antibody-analyte binding (stage 2), and bound antibody-GAR-HRP interaction (stage 3).

\subsection{Influence Assessment of Avidin and Biotin Components from Different Matrices}

Egg. Poultry eggs are real animal-derived samples among possible biotin-binding food matrices, which can be analyzed for antibiotic contaminants such as BT or COL. The maximum concentration of AVI in chicken egg is about $0.05 \%$ of the total egg protein (approximately $1800 \mu \mathrm{g}$ per egg) [33]. $\mathrm{B}_{7}$ is also found in eggs, about 7 and $50 \mu \mathrm{g}$ per $100 \mathrm{~g}$ of egg white and yolk, respectively $(20.7 \mu \mathrm{g}$ in a whole egg). Thus, both components of the egg are capable of interfering with the analysis. On the other hand, being components of one sample, they can partly quench each other's activity. However, their residual inhibitory activity on $\mathrm{SAV}-\mathrm{B}_{7}$ binding remains unknown. To estimate the inhibitory effect of extraneous $\mathrm{AVI} / \mathrm{B}_{7}$ from eggs on ELISAs for the detection of BT and COL, homogenates were prepared from eggs produced in poultry farms from seven different country regions (Leningrad Oblast, Nizhny Novgorod Oblast, Yaroslavl Oblast, Tula Oblast, Ryazan Oblast, Udmurtia, and Bashkortostan). Egg homogenates, 100-fold diluted with PBST, could inhibit the binding of the $\mathrm{B}_{7}$-labeled haptens to the SAV-coated wells when they were added together with the latter. Using standard curves (dashed lines from Figures 4 and 5), their resulting activity was measured and corresponded to an AVI average content of 90.6 $\pm 47.5 \mu \mathrm{g} / \mathrm{mL}$ (20.6-145.5) and to a $B_{7}$ average content of $1.98 \pm 0.92 \mu \mathrm{g} / \mathrm{mL}(0.56-3.0)$.

Milk formula. Milk itself contains negligible amounts of $B_{7}$, about $1 \mathrm{ng} / \mathrm{g}$ [15], but some infant formulas are fortified with vitamins. Two infant milk formula, "Agusha-1" and fermented milk formula "Agusha-2", which were used in recovery experiments of BT/COL, included $2 \mu \mathrm{g} \mathrm{B} 7$ per $100 \mathrm{~g}$ of product $(20 \mathrm{ng} / \mathrm{mL})$, as indicated by the manufacturer.

Liver. Animal liver is one of the richest sources of biotin [15]. Samples of chicken and beef liver were examined for their interference in the formation of the SAV-B $\mathrm{B}_{7}$-hapten complex and demonstrated inhibitory activity equivalent to $325 \pm 25 \mathrm{ng} / \mathrm{g}$ and $164 \pm$ $36 \mathrm{ng} / \mathrm{g}$, respectively.

Thus, the considered food matrices include a sufficient level of endogenous factors, $\mathrm{AVI}$ or $\mathrm{B}_{7}$, which can inhibit the binding of SAV- or $\mathrm{B}_{7}$-labeled reagents and distort the assay results. This was exemplified by the influence of the matrix at the stage of binding of the biotinylated hapten to the immobilized SAV. However, despite the stage of analyte recognition and the stage of SAV-B7 interaction being separated in the developed assay systems, the influence of endogenous matrix factors on the quantification of analytes was tested using standard BT and COL curves. 
3.6. Influence of $A V I$ and $B_{7}$ on the Quantification of BT and COL with ELISAs Based on the Coated $S A V-B_{7}-$ Hapten Complex

To simulate the effect of $\mathrm{AVI}$ and $\mathrm{B}_{7}$ contained in a matrix on the quantitative determination of BT and COL, we examined the calibration curves obtained using media enriched with these factors. Analyte standards were prepared in PBST and in buffer with the maximum expected concentration of the studied factors in food samples (AVI, 100,000 ng/mL, $\left.\mathrm{B}_{7}, 10-1000 \mathrm{ng} / \mathrm{mL}\right)$. The comparative study of standard curves generated in buffer and media containing AVI (Figure 6) and $B_{7}$ (Figure 7) revealed a discrepancy between the compared curves. These experiments with model AVI/ $B_{7}$-rich food matrices confirmed the interference of these endogenous factors in analyte quantification in (strept)avidin-based assays. This finding provides an explanation for the failure of the recovery of BT and COL from $\mathrm{AVI} / \mathrm{B}_{7}$-rich foodstuffs using these kinds of assays.
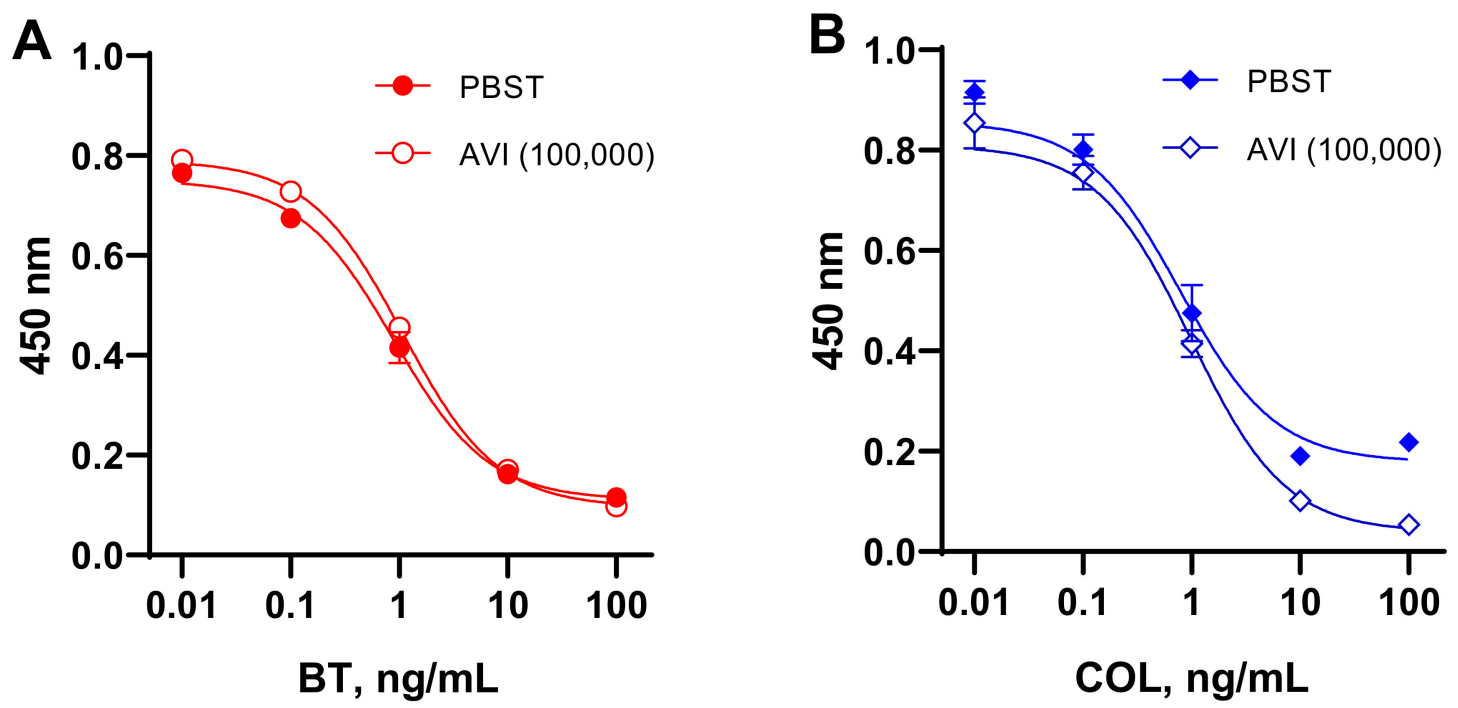

Figure 6. Standard curves for bacitracin (A) and colistin (B) determination in SAV-B 7 -hapten ELISAs generated in PBST and buffer enriched with avidin (AVI) at 100,000 ng/mL.
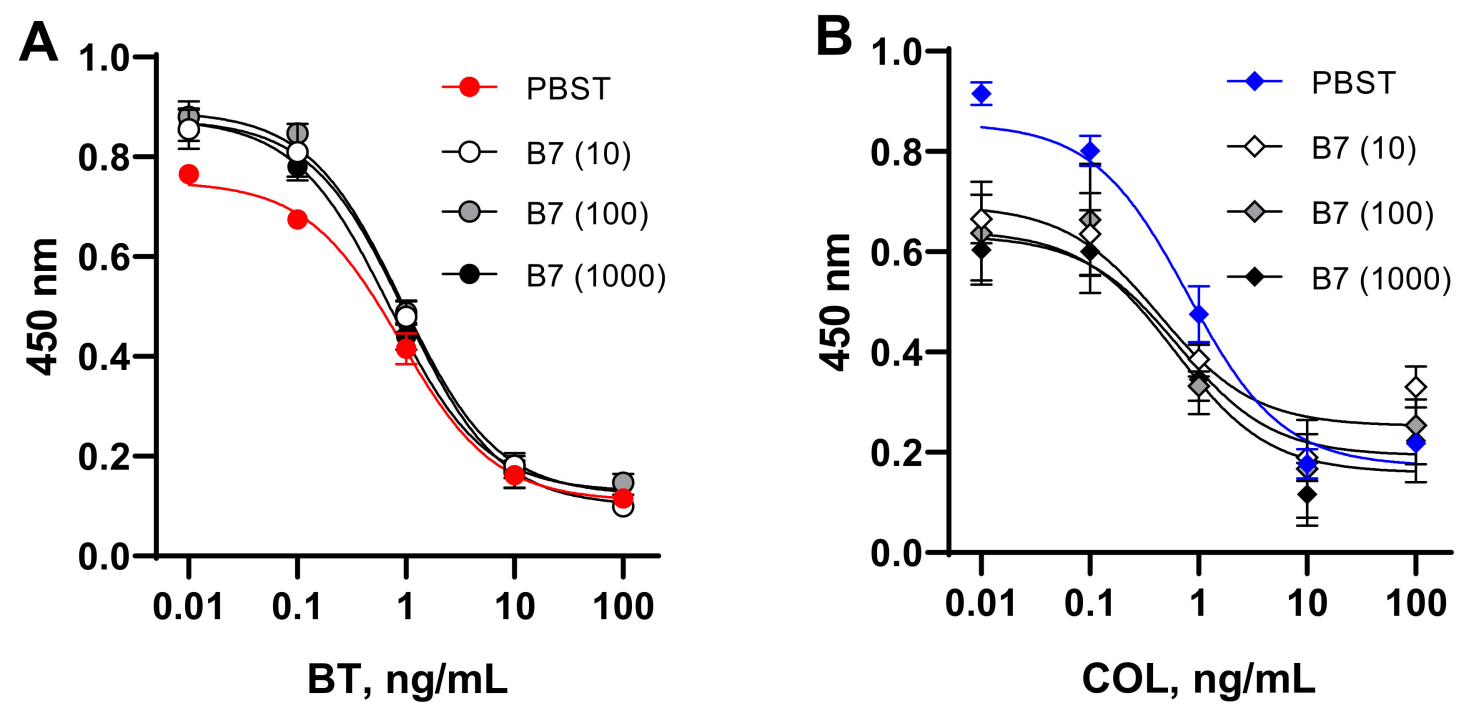

Figure 7. Standard curves for bacitracin (A) and colistin (B) determination in SAV-B 7 -hapten ELISAs generated in PBST and buffer enriched with biotin $\left(B_{7}\right)$ at 10,100 , and $1000 \mathrm{ng} / \mathrm{mL}$. 


\section{Conclusions}

An alternative approach for hapten coating on plates was realized using the oriented binding of biotinylated BT and COL to immobilized SAV. Such formed complexes and BT/COL conjugated to protein carriers were compared as coating antigens in competitive ELISAs for the determination of these cyclic peptide antibiotics in food matrices. The simple titration of $\mathrm{B}_{7}$-haptens in SAV-coated plates provided a finer optimization of coated hapten load compared with hapten load on the conjugates. Using the coating complexes SAV-B $7-B T$ and SAV-B $7-C O L$ instead of the coating conjugates GEL-BT(ae) and GEL(pi)PMB improved the sensitivity of the determination of BT and COL by 2 and 15 times, achieving 0.6 and $0.3 \mathrm{ng} / \mathrm{mL}$, respectively. The applicability of an immunoassay based on (strept)avidin-biotin interactions for the detection of analytes in food matrices rich in $\mathrm{AVI}$ or $\mathrm{B}_{7}$ was also challenged in this work. The possible interference of AVI or $\mathrm{B}_{7}$ from a matrix in different stages of the immunoassay was investigated. As a result, the developed competitive indirect ELISAs based on coated SAV-B $7-B T$ and SAV-B-COL, in addition to determining the main analytes, BT and COL, were applied for assessing AVI and $\mathrm{B}_{7}$ content in food matrices such as eggs, infant milk formula enriched with $\mathrm{B}_{7}$, and chicken and beef liver. Thus, due to the dose-dependent inhibition of the binding of $B_{7}$-hapten to SAV, these ELISAs proved to be suitable for solving additional analytical tasks, detecting AVI and $B_{7}$ up to 10 and $1 \mathrm{ng} / \mathrm{mL}$, respectively. The interaction between SAV and $B_{7}-$ hapten was the one most influenced by extraneous AVI and $B_{7}$. The detection of the analyte by an antibody occurs at different stages of the immunoassay, which minimizes the possible interference from $\mathrm{AVI}$ and $\mathrm{B}_{7}$ contained in the matrix. However, an adequate quantitative assessment of BT and COL in food matrices rich in $\mathrm{AVI} / \mathrm{B}_{7}$ was not implemented in the developed (strept)avidin-biotin-based immunoassays. Modification of the standard curves in a matrix-free but $\mathrm{AVI} / \mathrm{B}_{7}$-enriched environment provided evidence of the influence of these factors on the quantification of the analytes. This explains the failure of numerous recovery experiments with fortified nutritional matrices. Thus, summarizing the experience gained in the course of this study, it is recommended to avoid immunoassays based on avidin-biotin interactions when analyzing biosamples containing these factors.

Author Contributions: Conceptualization, Formal Analysis and Investigation, Writing-Original Draft Preparation, Review and Editing, M.A.B.; Formal Analysis and Investigation, Writing-Original Draft Preparation, I.A.G.; Funding Acquisition, Writing-Review and Editing, S.A.E. All authors have read and agreed to the published version of the manuscript.

Funding: This research was supported by the Interdisciplinary Scientific and Educational School of Moscow University «Future Planet and Global Environmental Change».

Institutional Review Board Statement: Not applicable.

Informed Consent Statement: Not applicable.

Data Availability Statement: The datasets used and/or analyzed during the current study are available from the corresponding author on request.

Conflicts of Interest: The authors declare no conflict of interest.

\section{References}

1. Wilchek, M.; Bayer, E.A. [54] Avidin-biotin mediated immunoassays: Overview. Methods Enzymol. 1990, 184, 467-469. [PubMed]

2. El-Maghrabey, M.; Kishikawa, N.; Harada, S.; Ohyama, K.; Kuroda, N. Quinone-based antibody labeling reagent for enzyme-free chemiluminescent immunoassays. Application to avidin and biotinylated anti-rabbit IgG labeling. Biosens. Bioelectron. 2020, 160, 112215. [CrossRef]

3. Mustafaoglu, N.; Alves, N.J.; Bilgicer, B. Oriented immobilization of Fab fragments by site-specific biotinylation at the conserved nucleotide binding site for enhanced antigen detection. Langmuir 2015, 31, 9728-9736. [CrossRef] [PubMed]

4. Ohashi, T.; Mawatari, K.; Kitamori, T. On-chip antibody immobilization for on-demand and rapid immunoassay on a microfluidic chip. Biomicrofluidics 2010, 4, 032207. [CrossRef] [PubMed]

5. Bratthauer, G.L. The avidin-biotin complex (ABC) method and other avidin-biotin binding methods. In Immunocytochemical Methods and Protocols; Springer: Berlin/Heidelberg, Germany, 2010; pp. 257-270. 
6. Cho, I.-H.; Bhunia, A.; Irudayaraj, J. Rapid pathogen detection by lateral-flow immunochromatographic assay with gold nanoparticle-assisted enzyme signal amplification. Int. J. Food Microbiol. 2015, 206, 60-66. [CrossRef]

7. Cohen, L.; Walt, D.R. Evaluation of antibody biotinylation approaches for enhanced sensitivity of single molecule array (Simoa) immunoassays. Bioconjugate Chem. 2018, 29, 3452-3458. [CrossRef] [PubMed]

8. Li, J.; Wagar, E.A.; Meng, Q.H. Comprehensive assessment of biotin interference in immunoassays. Clin. Chim. Acta 2018, 487, 293-298. [CrossRef] [PubMed]

9. $\quad$ Luong, J.H.; Male, K.B.; Glennon, J.D. Biotin interference in immunoassays based on biotin-strept (avidin) chemistry: An emerging threat. Biotechnol. Adv. 2019, 37, 634-641. [CrossRef]

10. Zempleni, J.; Wijeratne, S.S.; Hassan, Y.I. Biotin. Biofactors 2009, 35, 36-46. [CrossRef]

11. Jiang, W.; Beier, R.C.; Luo, P.; Zhai, P.; Wu, N.; Lin, G.; Wang, X.; Xu, G. Analysis of pirlimycin residues in beef muscle, milk, and honey by a biotin-streptavidin-amplified enzyme-linked immunosorbent assay. J. Agric. Food Chem. 2016, 64, 364-370. [CrossRef]

12. Sun, Z.; Lv, J.; Liu, X.; Tang, Z.; Wang, X.; Xu, Y.; Hammock, B.D. Development of a nanobody-aviTag fusion protein and its application in a streptavidin-biotin-amplified enzyme-linked immunosorbent assay for ochratoxin A in cereal. Anal. Chem. 2018, 90, 10628-10634. [CrossRef]

13. Lu, M.; Liang, M.; Pan, J.; Zhong, Y.; Zhang, C.; Cui, X.; Wang, T.; Yan, J.; Ding, J.; Zhao, S. Development of a Highly Sensitive Biotin-Streptavidin Amplified Enzyme-Linked Immunosorbent Assay for Determination of Progesterone in Milk Samples. Food Anal. Methods 2021. [CrossRef]

14. Zempleni, J.; Mock, D. Biotin biochemistry and human requirements. J. Nutr. Biochem. 1999, 10, 128-138. [CrossRef]

15. Staggs, C.; Sealey, W.; McCabe, B.; Teague, A.; Mock, D. Determination of the biotin content of select foods using accurate and sensitive HPLC/avidin binding. J. Food Compos. Anal. 2004, 17, 767-776. [CrossRef] [PubMed]

16. Stone, K.J.; Strominger, J.L. Mechanism of action of bacitracin: Complexation with metal ion and C55-isoprenyl pyrophosphate. Proc. Natl. Acad. Sci. USA 1971, 68, 3223-3227. [CrossRef] [PubMed]

17. Warren, H.S.; Kania, S.A.; Siber, G. Binding and neutralization of bacterial lipopolysaccharide by colistin nonapeptide. Antimicrob. Agents Chemother. 1985, 28, 107-112. [CrossRef] [PubMed]

18. Si, W.; Wang, L.; Usongo, V.; Zhao, X. Colistin induces S. aureus susceptibility to bacitracin. Front. Microbiol. $2018,9,2805$. [CrossRef] [PubMed]

19. Regulation, E.C. EU Council Regulation (2010) N 37/2010 of 22 December 2009 on pharmacologically active substances and their classification regardingmaximum residue limits in foodstuffs of animal origin. Off. J. Eur. Union 2010, L15, 1-72.

20. Hygienic Requirements in Respect of the Safety and Nutritional Value of Foodstuffs, SanPiN 2.3.2.1078-01, as Amended. Chapter 1. Requirements for the Safety and Nutrition of Foods of the Unified Sanitary-Epidemiological and Hygiene Requirements of the Commission of the Customs Union of Russia, Belarus and Kazakhstan. 2019. Available online: http:/ / docs.cntd.ru/document/ 902249109 (accessed on 10 December 2021).

21. Gaugain, M.; Raynaud, A.; Bourcier, S.; Verdon, E.; Hurtaud-Pessel, D. Development of a liquid chromatography-tandem mass spectrometry method to determine colistin, bacitracin and virginiamycin M1 at cross-contamination levels in animal feed. Food Addit. Contam. Part A 2021, 38, 1481-1494. [CrossRef]

22. Gaudin, V.; Hédou, C.; Rault, A.; Verdon, E.; Soumet, C. Evaluation of three ELISA kits for the screening of colistin residue in porcine and poultry muscle according to the European guideline for the validation of screening methods. Food Addit. Contam. Part A 2020, 37, 1651-1666. [CrossRef]

23. Li, Y.; Jin, G.; Liu, L.; Kuang, H.; Xiao, J.; Xu, C. A portable fluorescent microsphere-based lateral flow immunosensor for the simultaneous detection of colistin and bacitracin in milk. Analyst 2020, 145, 7884-7892. [CrossRef] [PubMed]

24. Byzova, N.A.; Serchenya, T.S.; Vashkevich, I.I.; Zherdev, A.V.; Sviridov, O.V.; Dzantiev, B.B. Lateral flow immunoassay for rapid qualitative and quantitative control of the veterinary drug bacitracin in milk. Microchem. J. 2020, 156, 104884. [CrossRef]

25. Galvidis, I.A.; Eremin, S.A.; Burkin, M.A. Development of indirect competitive enzyme-linked immunoassay of colistin for milk and egg analysis. Food Agric. Immunol. 2020, 31, 424-434. [CrossRef]

26. Kononenko, G.; Burkin, A. Methods of sanitary surveillance for livestock production. II. Enzyme immunoassay (EIA) of bacitracin. Agric. Biol. 2010; 6, 88-93.

27. Steinbuch, M.; Audran, R. The isolation of IgG from mammalian sera with the aid of caprylic acid. Arch. Biochem. Biophys. 1969, 134, 279-284. [CrossRef]

28. Galvidis, I.A.; Burkin, K.M.; Eremin, S.A.; Burkin, M.A. Group-specific detection of 2-deoxystreptamine aminoglycosides in honey based on antibodies against ribostamycin. Anal. Methods 2019, 11, 4620-4628. [CrossRef]

29. Burkin, M.; Galvidis, I. Simultaneous and differential determination of drugs and metabolites using the same antibody: Difloxacin and sarafloxacin case. Anal. Methods 2016, 8, 5843-5850. [CrossRef]

30. Burkin, M.; Galvidis, I. Immunochemical detection of apramycin as a contaminant in tissues of edible animals. Food Control 2013 34, 408-413. [CrossRef]

31. Burkin, M.; Galvidis, I. Development and application of indirect competitive enzyme immunoassay for detection of neomycin in milk. Appl. Biochem. Microbiol. 2011, 47,321-326. [CrossRef]

32. Burkin, M.A.; Galvidis, I.A.; Surovoy, Y.A.; Plyushchenko, I.V.; Rodin, I.A.; Tsarenko, S.V. Development of ELISA formats for polymyxin B monitoring in serum of critically ill patients. J. Pharm. Biomed. Anal. 2021, 204, 114275. [CrossRef]

33. Green, N.M. Avidin. In Advances in Protein Chemistry; Elsevier: Amsterdam, The Netherlands, 1975; Volume 29, pp. 85-133. 
34. Taskinen, B.; Zmurko, J.; Ojanen, M.; Kukkurainen, S.; Parthiban, M.; Määttä, J.A.; Leppiniemi, J.; Jänis, J.; Parikka, M.; Turpeinen, H. Zebavidin-An avidin-like protein from zebrafish. PLoS ONE 2013, 8, e77207. [CrossRef]

35. Määttä, J.A.; Helppolainen, S.H.; Hytönen, V.P.; Johnson, M.S.; Kulomaa, M.S.; Airenne, T.T.; Nordlund, H.R. Structural and functional characteristics of xenavidin, the first frog avidin from Xenopus tropicalis. BMC Struct. Biol. 2009, 9, 1-13. [CrossRef] [PubMed]

36. Chaiet, L.; Wolf, F.J. The properties of streptavidin, a biotin-binding protein produced by Streptomycetes. Arch. Biochem. Biophys. 1964, 106, 1-5. [CrossRef]

37. Helppolainen, S.H.; Nurminen, K.P.; Määttä, J.A.; Halling, K.K.; Slotte, J.P.; Huhtala, T.; Liimatainen, T.; Ylä-Herttuala, S.; Airenne, K.J.; Närvänen, A. Rhizavidin from Rhizobium etli: The first natural dimer in the avidin protein family. Biochem. J. 2007, 405, 397-405. [CrossRef] [PubMed]

38. Takakura, Y.; Tsunashima, M.; Suzuki, J.; Usami, S.; Kakuta, Y.; Okino, N.; Ito, M.; Yamamoto, T. Tamavidins-novel avidin-like biotin-binding proteins from the Tamogitake mushroom. FEBS J. 2009, 276, 1383-1397. [CrossRef] [PubMed]

39. Takakura, Y.; Sofuku, K.; Tsunashima, M.; Kuwata, S. Lentiavidins: Novel avidin-like proteins with low isoelectric points from shiitake mushroom (Lentinula edodes). J. Biosci. Bioeng. 2016, 121, 420-423. [CrossRef] 